Department by ambulance requires more resources than does the patient who walks into the Emergency Department. Hence, it is important to know the pattern of ambulance arrivals for judicious utilisation of limited resources, so as to plan for future resource allocation.

Method: This is a retrospective study of all ambulance arrivals in the Emergency Department of Tan Tock Seng Hospital in 1996. The following data of each attendance were abstracted from computer records: 1) demographic data; 2) the number of ambulance arrivals by hour, emergency or non-emergency, trauma or non-trauma; 3) cause of injury for trauma cases; 4) discharge status; and 5) turn-around time (time from arrival to disposal in the Accident and Emergency Department (A \& E).

Where relevant, these data were compared to those of the walk-in patients and with the total arrivals of the same year. The total numbers of ambulance cases brought to the A \& E Department of the six governmental acute hospitals in Singapore in 1996 was obtained from the Summary Analysis of Work Done in Public Sector Hospitals, Primary Health Care and Dental Clinics 1996 issued by the Ministry of Health.

Results: The Department of Emergency Medicine in our hospital evaluated 110,584 patients in 1996, which accounted for $19.8 \%$ of the total Emergency Department attendance in Singapore: the second busiest emergency department for that year. $12.4 \%$ (13,697 cases) came by ambulance. This constituted $27 \%$ (the highest) of the total ambulance cases brought to the six A\&E Departments of the acute hospitals in Singapore in 1996. $61.2 \%$ and $38.8 \%$ were male and female patients respectively. The majority of the patients $(68.5 \%)$ were Chinese. The age distribution of the ambulance and walk-in arrivals is listed in Table 1.

Table 1-Age Distribution of Ambulance and Walk-in Arrivals

\begin{tabular}{lrr} 
& Ambulance & \multicolumn{1}{c}{ Walk-in } \\
Number of Arrivals & 13,697 & 96,887 \\
Age, $<12$ years (\%) & 8.2 & 21.8 \\
Age, 13-19 years (\%) & 7.2 & 8.1 \\
Age, 20-59 years (\%) & 46.6 & 53.0 \\
Age, $>60$ years (\%) & 37.4 & 17.1
\end{tabular}

The majority (98.5\%) was classified as emergencies following the guidelines provided by the Ministry of Health, Singapore. $40.7 \%$ of the ambulance arrivals were due to trauma versus $27.3 \%$ of the walk-in arrivals. The majority of the ambulance trauma cases were brought in because of road traffic accidents (15.3\%) or home accidents $(7.4 \%)$. The peak in ambulance arrivals was between $21: 00 \mathrm{~h}-23: 00 \mathrm{~h}$ compared to $10: 00 \mathrm{~h}-12: 00 \mathrm{~h}$ for the walk-in arrivals.

The median turnaround time for an ambulance case was 30 minutes, which compares to 43 minutes for all cases seen in the A \& E Department. The majority $(53.7 \%)$ of ambulance arrivals was admitted, and $31.8 \%$ were treated and discharged.

Conclusion: There was a larger proportion of patients $>60$ years old brought in by ambulance than in the walkin population. This would support the view that our older patients were more ill and required more resources.
Hence, in the future planning of resource allocation like staff deployment and purchase of equipment and in the development of contingency plans, emphasis will be placed on the resource usage of ambulance arrivals, and we will use the pattern of their arrivals as an aid.

Keywords: Accident and Emergency Department; age; ambulance; arrival mode; injuries; planning; walk-in

\section{P-15 \\ Prehospital Medical Treatment in the County of Östergötland, Sweden}

Rune G. Blomberg, MD, PbD; Björn Hansson,

Hospital Quality Coordinator Disaster Management Committee, Central Hospital, Norrköping, Sweden

Background: The county of Östergötland in southern Sweden has a population of around 414,000 of whom 298,000 live in the three towns with a hospital. The county has an area of 10,500 square kilometres, and consists of three districts: 1) the western (with a county hospital); 2) the central (with a university hospital); and 3) the eastern (with a large central hospital). The three hospitals keep medical teams prepared to be dispatched 24 hours every day in order to response to an alert. Each team consists of a trained doctor and nurse with protective clothing and necessary medical equipment for prehospital treatment. Additional teams from 11 primary care centres are available during office hours and are able to be assisted by a team from the nearby hospital. The alert always is conveyed by the county SOS Emergency Centre.

Aim: In 1998, a survey was performed of the complete activities of the teams with special attention to the medical procedures applied, time data of the response, and to methods of transportation. An attempt was made to evaluate the effects of the prehospital treatment on the outcome of each patient.

Methods: A special written report was made at each occasion by both the hospital and/or primary care centre and by the team alerted stating the time data concerned and the medical treatment applied. Comparisons were made to the ambulance report and to the report from the county Alert Centre, the SOS Emergency Centre. Finally, hospital records of the patients treated were scrutinised in order to evaluate the procedures and the outcome.

Results: (preliminary): Up to 31 October, 1998, the teams of the county had responded to 97 alerts. The alert for the medical team was canceled before or during the response in 34 instances. Thus, 63 responses were fulfilled, 38 of which were caused by traffic accidents. The response by the team was achieved within 5 minutes in 22 instances and between 5 and 10 minutes in 24 instances. Existing data for 48 responses show total time consumed to be $<30$ minutes in 5 instances, $30 \leq 60 \mathrm{~min}-$ utes in 22 and $>1$ hour in 21 instances.

Medical procedures performed together with the ambulance staff in the 63 responses were: intravenous line and infusion of Ringer's solution, 31; administration of analgesics/sedatives, 8; maintenance of airway, 7; 
cardiopulmonary resuscitation, 5 (none successful); control of gross bleeding, 2; reposition of fracture, 1. Fiftyone hospital records have been examined up to now provided evidence that the prehospital measures were life-saving in three subjects and contributed to stabilisation of the patient's condition preventing deterioration prior to hospital admission in another 18 subjects. Conclusions: The time from the alert to team response was short in view of the fact that the personnel always were engaged in routine medical work prior to the alert. Methods of transportation (from fire department or ambulance) were adequate. The number of cancellations was annoyingly large, especially in the central district. Measures are needed to increase the accuracy of the alert. The time consumed in the responses was such as to cause delays in routine hospital work, especially during off-office hours. Such a drawback might be relieved by increasing the number of personnel engaged. Medical procedures were judged to be adequate showing sufficient basic training of personnel in disaster medicine. It is our opinion that the teams are a necessary part of the medical obligations of the community.

The complete figures for the year of 1998 will be presented at the Congress of WADEM, where updated data will be available.

Keywords: alert; effects of treatment; medical teams; primary care; procedures; response times; total time

\section{General Session XVI \\ Mass Gathering \\ Wednesday, 13 May, 14:50-16:20 hours \\ Chair: Se Kyung Kim, Noriyoshi Ohashi}

\section{G-76}

Mass Casualty in a Pop Music Concert Instead of Being a Programmed Event: Home Fair 1997, Lima, Peru

Moncerrat Orue, $M D$; Roberto Pretell, $M D$

Assisted Transport Emergency System (STAE), Peruvian Social Security Institute, Lima, Peru

Introduction: On 05 August 1997, the main show of the Home Fair 1997 program was provided by two young Venezuelan singers of tropical music, who were very popular with Peruvian teenagers in that time. As a consequence of bad organization and the fanaticism of the young adolescents, four female teenagers and one male died, and approximately 1,000 people were injured. The open auditorium that has an approximate capacity for 20,000 was filled with 100,000 people. The Assisted Transport of Emergency System and other organizations were responsible for the medical assistance and help facilities for that programmed event.

Purpose: To analyze the conditioning factors for mass casualties at a programmed event, and to formulate recommendations about the management of this kind of events.

Methods: Descriptive methods were used to gather data. The prehospital record sheet for responses by The
Assisted Transport System (STAE) was revised. Additional data were obtained from the hospitals to which the victims were referred.

Results: Instead of this event following the path programmed in previous meetings for coordinating actions, on the day of the concert, the situation ran out of control with the tragic result of the deaths of five adolescents. The average age of the victims was 17 years (range: 15-19 years). Four of the victims were women and one was a man. The STAE was in charge of assisted transport and attended a total number of 43 patients, two of them arrived dead to the hospital; 39 were women (90.7\%), four (9.3\%) were men. The main injuries were: multiple contusions, acute respiratory failure, limb trauma, thoracic trauma, and abdominal trauma. The others three deaths occurred within five days after the event. The approximate number of injuries was 1,000 , the majority of them as a consequence of the mass pressure against the people who wanted to be closer to their idols. The main cause of death was traumatic asphyxia. There were no case of cranial trauma.

Conclusion: The disaster was imminent many hours before the concert began. The organizers did not want to cancel it despite of the recommendations made by the Health Commission and the STAE. The main pathology was the trauma and traumatic asphyxia, the principal cause of death. We will discuss recommendations to prevent these kinds of problems, and to prevent disasters of this magnitude.

Keywords: asphyxia; crowds; injuries; mass gathering; planning; trauma; traumatic asphyxia

\section{G-77}

Treat and Release: A New Approach to the Emergency Medical Needs of the Oldest Mass Gathering - the Pilgrimage

Mawafag Al-Bayouk, MD; Prof. Mahammed Seraj, MD; Ibrahim Al-Yamani, EMT-Paramedic;

Sulaiman Al-Gufaidi, EMT-Paramedic

Department of Anesthesiology, College of Medicine, King Saud University, Saudi Arabia

The Pilgrimage season in the Holy Land of Makkah possibly is the largest and oldest mass gathering known to mankind. In this activity, at least 2.5 -million persons from all of the Muslim countries perform a pilgrimage (Haji) that requires their presence at specific areas at the same time for a period of 5-7 days. This leads to a high population density that reaches $8-9$ persons per square meter.

Like all mass gatherings, the need for emergency medical care was recognized and preparations were made by the Saudi Red Crescent Society (SRCS), the agency responsible for emergency medical services (EMS) in the Kingdom of Saudi Arabia. The plan of the SCRS for the coverage was to respond to all emergency calls through a dispatcher system. Review of this system for a period of five years indicated that the main task was to transfer all patients $(7,000-9,000$ per year) to the nearest emergency center. The trip time (from dispatch 